\title{
Cateterización por punción de la vena subclavia en niños
}

\author{
Drs. Acuña D., Santander C., Enriquez O., Gyhra A, Israel J.
}

\begin{abstract}
ABSTHACT
Forty cases of subclavian vein catheterization, in children, were studied prospectively. The technic is described, and also factors as age, thme of permanence of catheter, complications and indications, concluding that the method ofers the same perspectives than in adults.
\end{abstract}

En la práctica médica actual, una vía venosa que pueda mantenerse por un tiempo relativamente largo y que sea cómoda para el personal médico y el enfermo, constituye una gran facilidad terapéutica. La cateterización de la vena subclavia cumple estos requisitos y una vez que se obtiene seguridad y precisión en su maniobra se convierte en un procedimiento relativamente fácil de efectuar.

Relatamos nuestra experiencia en 40 cateterizaciones de vena subclavia en niños, realizadas en el Hospital Gmo. Grant Benavente, de Concepción, en el periodo enero a octubre de 1979.

\section{MATEAIAL Y METODO}

Se practicaron 40 punciones en niños cuyas edades fluctuaron entre 6 meses y 8 años.

Téenica: Se utiliza un Catéter DESERET N. ${ }^{\circ}$ 3174 , de $30 \mathrm{~cm}$., con guía metálica con el objeto de obtener una ubicación segura en la vena cava superior. La punción se realiza, previa anestesia local de la zona media infraclavicular. Por razones de anatomía ${ }^{2}$ preferimus el lado derecho.

El paciente se coloca en decúbito dorsal, con una almohadilla entre las escápulas y la cara dirigida al lado opuesto a la punción.

Depto. de Cirugía Esc. de Medicina Liniversidad de Concepc.jón.

Servicau de Cirugia flospita] Gino. Grant Benavente.
El trócar con jeringa y suero fisiológico y con el bisel dirigido hacia abajo entra en dirección a la Horquilla estemal rozando el borde inferior de la clavicula. Una vez puncionada la vena Subclavia se introduce el Catéter preformado, el que se introduce $6-10 \mathrm{~cm}$. dependiendo del tamaño $\mathrm{y}$ edad del niño, de tal manera que la punta del catéter quede ubicado en la vena cava sup.; se fija el catéter a la piel con un punto de bilo y se protege el sitio de entrada con furacin y curación hermética.

Se completó un protocolo en cada caso, de tal manera que se obtuvo un estudio uniforme $y$ prospectivo.

\section{RESULTADOS}

Se instalaron 40 catéteres en 31 pacientes. $16 \mathrm{ds}$ sexo masculino y 15 femeninos. Sus edades fluctuaron entre 6 meses y 8 años. La distribución por edad se observa en Fig. 1.

En 25 pacientes se realizó solo una cateterización. En 3 niños se realizaron 2 cateterizaciones, uno por tratamiento E.V. prolongado, otro por obstrucción del catéter y un tercero por salida accidental de éste. En 3 niños se realizaron 3 cateterizaciones alternadas ou por necesidad de un tratamiento E.V. prolongado. Cuadro $l$.

Las indicaciones de instalar un catéter subclavio se resumen en el Cuadro 2. 
Fig. 1

\section{DISTRIBUCION POR EDAD}

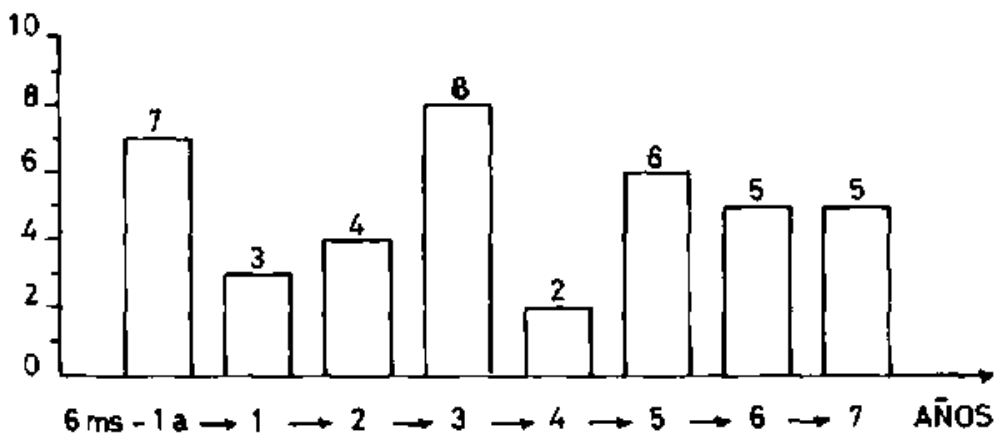

Cuadro 1

NUMERO DE CATETERIZACIONES REALIZADAS POR PACIENTE

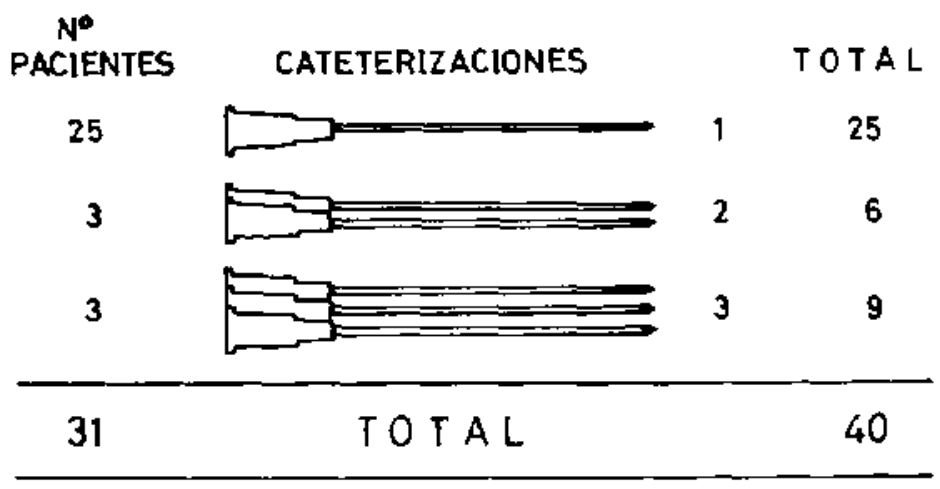

Cuadro 2

INDICACIONES DE LA CATETERIZACION

\begin{tabular}{|c|c|c|c|}
\hline \multirow[b]{2}{*}{ PROCESO SEPTICO GRAVE } & \multicolumn{2}{|c|}{ Casos } & $\%$ \\
\hline & 15 & WIIZZZZZ & 37.5 \\
\hline MENINGITIS & 5 & EZZ & 12.5 \\
\hline TERAPIA PROLONG E.V. INTENSIVA & 5 & WD & 12.5 \\
\hline GRAN CIRUGIA & 4 & $\mathbb{Z Z}$ & 10.0 \\
\hline POLITRAUMATIZADO GRAVE & 3 & $\mathbb{Z}$ & 7.5 \\
\hline ENF. REUMATICA - ENDOCARDITIS & 2 & 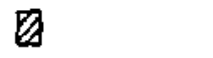 & 5,0 \\
\hline OTAAS & 3 & $\mathbb{Z}$ & 7.5 \\
\hline TOTAL & 40 & & \\
\hline
\end{tabular}


Es necesario destacar que el procedimiento se intentó en 46 oportunidades. En 34 casos se instaló el catéter en el primer intento. En 2 casos hubo puncion arterial, pero se logro la cateterización venosa en el lado opuesto. En 2 niños el primer intento en el lado derecho fue fallido, pero se logro una cateterización sin problemas en el lado opuesto. En 2 niños el procedimiento no pudo obtenerse a pesar de puncionar ambos lados.

Las indicaciones para retirar el catéter se resumen en el Cuadro 3.

20 de los 40 catéteres colocados fueron enviados a examen bacteriológico. Los resultados se exponen es el Cuadro 4.

El período de duración de la cateterización se resume en el Cuadro 5.

\section{DISCUSION}

Nuestra experiencia nos indica que el contar con una vía venosa en el niño, obtenida por punción y cateterización de la vena subclavia, no muestra diferencias significativas con las dificultades têcnicas, manejo y complicaciones que se describen en el adulto. 2,3

Creemos necesario insistir en realizar la cateterización con instumental adecuado, el no contar con éste favorece el número de complicaciones e intentos fallidos.

Nos parece interesante destacar que en los 4 casos en que se cultivó gérmenes patógenos, los pacientes no presentaron sintomatología que se relacionara con ese hecho.

Cuadro 3

CAUSA DE RETIRO DE LOS 40 CATETERES

\begin{tabular}{|c|c|c|c|}
\hline & Cas & & $\%$ \\
\hline TERMINO DE TRATAMIENTO & 27 & & 67,5 \\
\hline FALLECIMIENTOS & 6 & $\square$ & 15.0 \\
\hline OBSTRUCCION DEL CATETER & 3 & $\square$ & 7,5 \\
\hline RETIRO ACCIDENTAL & 2 & $\square$ & 5,0 \\
\hline $\begin{array}{l}\text { HEMORRAGIA EN EL SITIO DE } \\
\text { CATETERIZACION }(*)\end{array}$ & & $\square$ & 5,0 \\
\hline
\end{tabular}

Cuadro 4

BACTERIOLOGIA EN 20 CASOS

\begin{tabular}{|c|c|}
\hline & $\mathrm{Ca}$ \\
\hline NEGATIYO & 10 \\
\hline GERMENES SAPROFITOS & 4 \\
\hline GERMENES PATOGENOS $(*)$ & 4 \\
\hline $\begin{array}{l}\text { G. POTENCLALMENTE PATOGENOS } \\
\text { (**) }\end{array}$ & 2 \\
\hline
\end{tabular}

(*) Klebsiella en dos y Pseudomona aeruginosa

(*x) Levaduras y Staphylococo epidermis. 


\section{DURACION DE LA CATETERIZACION}

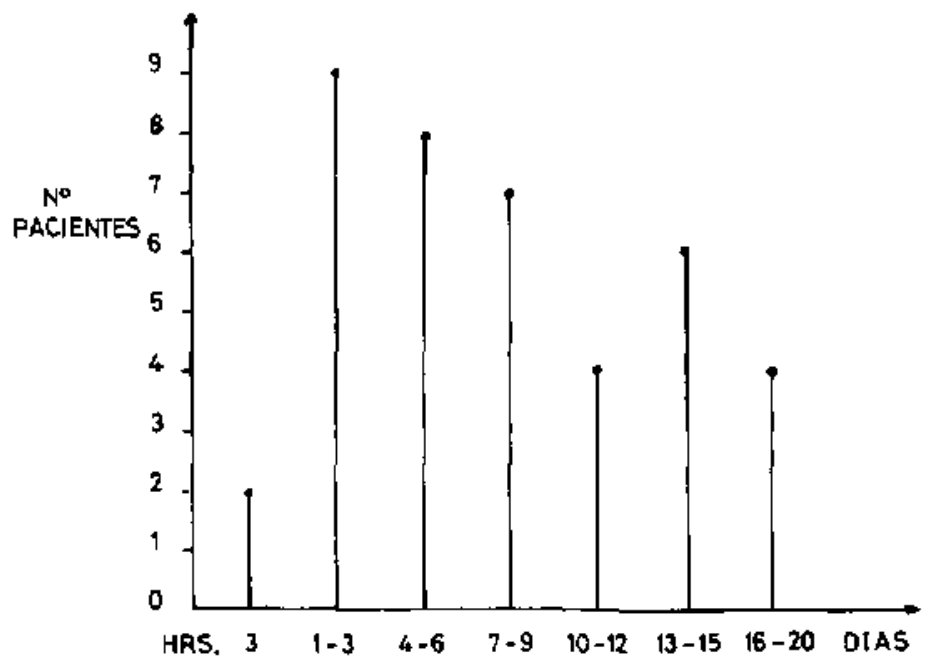

Esta vía venosa de altemativa ha sido de gran utilidad en nuestro equipo evitando un múmero importante de denudaciones venosas, un fácil manejo por el personal de enfermería y gran comodidad para el paciente.

\section{RESUMEN}

Se presentan 40 casos de Cateterización de vena subclavia en niños con un estudio prospectivo, se describe la técnica, se analizan factores como edad, tempo de permanencia del catêter, com- plicaciones, indicaciones para su instalación y se concluye que es un método que ofrece las mismas perspectivas que en el adulto.

\section{REFERENCLAS}

lGuarda L., Jung W., Punción y Cateterización Subclavia. Boletin del Hospital San Jurn de Dios. 20: 6, 311. 1973.

${ }^{2}$ Fijas H., Power E., Rivera R., Encina L. La Cateterización de la Vena Cava Superior vía Subclavia. Boletín del Hospital San Juan de Dios 25: 5, 253. 1978.

${ }^{3}$ Herbot $\mathrm{Ch}$. Indication, management and Complication of Parentaneous Subclavien catheters. Archives of Sugery. 113: 13. 1421. 1978. 